\title{
Biosseguridade para sistemas de produção de peixes em tanque-rede em função da colmatação agravada por Limnoperna fortunei
}

\author{
[Biosecurity for fishfarming cage systems due to the highly clogged screen aggravated \\ by Limnoperna fortunei] \\ G.R. Vianna ${ }^{1}$, T.M. Oliveira ${ }^{1}$, E.A. Teixeira ${ }^{1}$, R.R. Nicolino ${ }^{2}$, W.R. Boscolo ${ }^{3}$, \\ M.X. Silva ${ }^{1}$, J.P.A. Haddad ${ }^{1}$ \\ ${ }^{1}$ Universidade Federal de Minas Gerais - Belo Horizonte, MG \\ ${ }^{2}$ Universidade Federal dos Vales do Jequitinhonha e Mucuri - Unaí, MG \\ ${ }^{3}$ Universidade Estadual do Oeste do Paraná - Cascavel, PR
}

\begin{abstract}
RESUMO
Este trabalho avaliou a colmatação por Limnoperna fortunei em diferentes materiais para confecção de telas de arame, a dinâmica da colmatação pelo molusco e a relação custo-benefício dos materiais usados em tanques-rede. Utilizaram-se amostras de telas de simples torção de malha $19 \mathrm{~mm}$, de cinco tipos diferentes de revestimentos, colocadas na barragem de Salto Caxias, no Rio Iguaçu, estado do Paraná, entre julho de 2012 e julho de 2014. A cada seis meses, foi verificado o ganho de peso das telas em razão da colmatação, além da contagem do número de mexilhões aderidos. Após as coletas dos dados, foi realizado o teste estatístico de Kruskal-Wallis para se avaliar o ganho de peso das telas devido à colmatação. Realizou-se também uma pesquisa com 21 empresas para se obter o preço comercializado de telas para confecção de tanques-rede e se avaliar a expectativa de durabilidade dos materiais. Verificou-se que os diferentes materiais avaliados para as telas influenciam na colmatação e aderência do mexilhãodourado; além disso, constatou-se que a tela mais eficiente quanto ao custo/ano é a de arame galvanizado plastificado e, para baixa colmatação, a de arame Bezinal.
\end{abstract}

Palavras-chave: aquicultura, colmatação, Limnoperna fortunei, mexilhão-dourado, tanque-rede

\begin{abstract}
This research evaluated degree of clogging by Limnoperna fortunei in different materials for wire mesh fabrication, the dynamics of mollusk sealing and the cost-benefit ratio of these materials used in tanknets. Samples of single-twist screens of $19 \mathrm{~mm}$ mesh were used, from five different types of coatings were placed in the Salto Caxias dam on the Iguaçu River in the Paraná state, between July 2012 and July 2014. Every six months, it was verified the weight gain of the screens due to clogging and counting of the number of mussels adhered. After the data collection was performed Kruskal-Wallis statistical test to evaluate the weight gain of the screens due to clogging. In addition, a survey was carried out with 21 companies to obtain the commercialized price of screens for the production of net tanks and to evaluate the expected durability of the materials. The different materials evaluated for the screens influenced the sealing and adhesion of the golden mussel. In addition, the most cost-per-year screen is that of plasticcoated galvanized wire and for low clogging it is the Bezinal wire.
\end{abstract}

Keywords: aquaculture, clogging, Limnoperna fortunei, golden mussel, tank-net

\section{INTRODUÇÃO}

A produção brasileira de peixes tem crescido a cada ano, impulsionada pela existência de novos empreendimentos, pelos investimentos em novas tecnologias, pela melhoria do manejo e do processo produtivo. Segundo o IBGE (Produção..., 2015), a piscicultura brasileira produziu 483,24 mil toneladas de pescado, um aumento de $1,5 \%$ na produção em comparação com o ano de 2014, atingindo uma receita bruta de $\mathrm{R} \$ 3,06$ bilhões.

Recebido em 18 de outubro de 2017

Aceito em 16 de maio de 2018

E-mail: guilherme.vianna@belgobekaert.com.br 
A tendência, nos próximos anos, é o aumento do consumo de pescados no mundo, o que torna a aquicultura um segmento muito atrativo (The State..., 2009). O sistema de produção de peixes em tanque-rede (TR) tem-se difundido amplamente no Brasil devido às condições ambientais favoráveis, à abundância de recursos hídricos com reservatórios naturais e artificiais e à disponibilidade de grãos para o processamento de rações balanceadas (Borghetti et al., 2003; Ostrensky et al., 2008).

No Brasil, o modelo dominante atualmente é o tanque-rede retangular de oito metros cúbicos, flutuante, com tela de arame galvanizado revestido em cloreto de polivinila (PVC) (Boletim..., 2010). É desejável que os materiais do tanque-rede tenham um padrão de qualidade, sendo leves, com resistência mecânica adequada, com durabilidade frente à corrosão, de fácil aquisição no mercado, com histórico de funcionalidade reconhecida, não abrasivo aos peixes, que facilite a passagem de água pela malha da tela e que tenha um custo adequado à proposta do projeto (Chagas et al., 2002; Ono e Kubitza, 2003; Beveridge, 2004).

O sistema de produção de peixes em tanque-rede cresceu na última década, impulsionado especialmente pela produção de tilápia em criatórios de pequeno e médio porte. Isso contribuiu para que, no ano de 2008, a piscicultura em tanque-rede representasse cerca de $8 \%$ (1452 unidades) dos empreendimentos aquícolas e $30 \%$ do volume de produção no Brasil (Kubitza, 2003; Brabo et al., 2014).

A produção de peixe em tanque-rede é um sistema de alta densidade, dependente exclusivamente de grande renovação de água. As telas dos tanques-rede precisam ser eficientes, a fim de permitir essa renovação de água, duráveis, resistentes, conferindo alta biosseguridade e uma boa relação de custo/benefício. Quando a tela de um tanque-rede apresenta alto grau de colmatação por aderência de mexilhão-dourado, há queda da qualidade e disponibilidade da água em razão do seu menor fluxo de passagem, proporcionando uma baixa renovação.

Os problemas de natureza nutricional, zootécnica e sanitária ocorreram com maior frequência na década de 1980, causados principalmente pela falta de investimento e pelo desconhecimento da tecnologia por parte de produtores e técnicos. No entanto, na década seguinte, o surgimento de linhagens e híbridos com melhores índices zootécnicos e de rações extrusadas de alta digestibilidade proporcionou a consolidação desse setor no território brasileiro (Ostrensky et al., 2008; Scorvo Filho et al., 2010; Brabo et al., 2014). A produção aquícola mundial é vulnerável a doenças e problemas relacionados ao sistema produtivo. Segundo o Código Sanitário para Animais Aquáticos, entre os anos de 2012 e 2013 havia 10 doenças emergentes de peixes, que poderiam comprometer seriamente $\mathrm{o}$ fornecimento de proteína de pescado (Aquatic..., 2013; Oie..., 2014).

Limnoperna fortunei é um molusco bivalve de água doce, da família dos mitilídeos, dioico, filtrador e com duas características muito marcantes: rápida maturação sexual e elevada capacidade reprodutora (Darrigran et al., 2000; Silva e Souza, 2004). Essa espécie é considerada invasora e, quando introduzida em um novo ambiente, tem capacidade de se adaptar, reproduzir e competir com as espécies existentes do local (Chomel, 2010). O L. fortunei foi introduzido na América do Sul, por meio de águas de lastro de navios cargueiros vindos do sul da Ásia, no início da década de 1990, tendo sido sua notificação realizada no Brasil em 1998 (Silva e Souza, 2004; Oliveira et al., 2004).

A colmatação (acúmulo de algas, moluscos e sólidos suspensos nas telas) causada pelo $L$. fortunei vem se tornando um grave problema e inviabilizando o sistema de tanques-rede em vários reservatórios brasileiros (Oliveira et al., 2004; Silva e Souza, 2004). O mexilhão-dourado tem o hábito de aderir-se a vários substratos presentes nos corpos d'água, inclusive na tela do tanque-rede, aumentando o peso da estrutura, dificultando o manejo, impedindo a renovação da água devido à obstrução da malha da tela e aumentando a pressão de arraste (Arana, 1999; Beveridge, 2004; Plano..., 2014).

Programas de controle e erradicação da colmatação são escassos, no entanto a sua implementação poderia melhorar a produtividade em tanques-rede. Um método de baixo custo para o controle do mexilhãodourado aderido usado em algumas pisciculturas é a exposição da tela ao ar. Outros métodos de controle podem ser implementados por meio de 
algumas espécies de peixes nativos, como o Pterodoras granulosus (Silva e Souza, 2004), e tintas anti-incrustantes à base de cobre (Hellio e Yebra, 2009), apesar do risco de causar contaminação ambiental (Castro et al., 2011). Outros estudos sugerem o monitoramento da espécie invasora, a limpeza dos cascos de embarcações e ações educativas junto aos produtores e à população local (Oliveira et al., 2004; Souza et al., 2009). Para Oliveira et al. (2004), o ideal é trabalhar com programas de prevenção e, assim, evitar que o mexilhãodourado seja transportado por embarcações e consiga aderir à tela do tanque-rede, a fim de reduzir ou retardar, a colmatação. Considerando os impactos causados pelo $L$. fortunei na produção de peixes em tanques-rede e a escassez de trabalhos nessa área, o presente estudo teve como objetivo descrever a dinâmica de desenvolvimento da colmatação pelo molusco invasor L. fortunei nos tanques-rede, avaliar a colmatação em diferentes tipos de tela de arame empregados na confecção dos tanques e verificar a relação custo-benefício dos materiais utilizados.

\section{MATERIAL E MÉTODOS}

O estudo foi realizado no lago da barragem Governador José Richa, no rio Iguaçu, localizado no município de Boa Vista da Aparecida, PR, entre julho de 2012 e julho de 2014. Essa região pertence à bacia do rio da Prata, estendendo-se pelo Brasil, Uruguai, Bolívia, Paraguai e Argentina, sendo considerada a segunda maior bacia hidrográfica do Brasil, com $1.397 .905 \mathrm{~km}^{2}$, e a décima em vazão do mundo. A escolha desse local de estudo esteve relacionada à sua importância econômica, aos registros da presença do L. fortunei e aos problemas de colmatação causados pelo mexilhão-dourado (Oliveira et al., 2004; Silva e Souza, 2004).

Neste estudo, foram utilizadas telas com malha de $19 \mathrm{~mm}$ e espessuras que variaram de 1,60 a 1,90mm para confeccionar os modelos de tanque-rede usando a técnica de simples torção, segundo a ABNT, NBR-10118, comercialmente chamada de tela tipo alambrado (Associação..., 2013). Os modelos de tela testados e suas especificações estão representados na Tab. 1.

Tabela 1. Especificações dos modelos das telas selecionadas para o estudo

\begin{tabular}{|c|c|c|c|c|c|}
\hline Modelo de tela testada & $\begin{array}{c}\text { Nome abreviado } \\
\text { do corpo de } \\
\text { prova }\end{array}$ & $\begin{array}{l}\text { Quantidade } \\
\text { de amostras } \\
\text { (peça) }\end{array}$ & $\begin{array}{c}\text { Peso } \\
\text { médio } \\
\text { inicial }(\mathrm{g})\end{array}$ & $\begin{array}{c}\text { Largura } \\
\mathrm{da} \\
\operatorname{amostra}(\mathrm{cm})\end{array}$ & $\begin{array}{c}\text { Comprimento } \\
\text { da amostra }(\mathrm{cm})\end{array}$ \\
\hline $\begin{array}{l}\text { Tela de arame } \\
\text { galvanizado } \\
\text { plastificado } 1,90 \mathrm{~mm}\end{array}$ & TAP & 32 & 848 & 30 & 200 \\
\hline $\begin{array}{l}\text { Tela de arame } \\
\text { galvanizado } \\
\text { plastificado } 1,90 \mathrm{~mm} \\
\text { com tinta anti- } \\
\text { incrustante }\end{array}$ & TAPP & 32 & 898 & 30 & 200 \\
\hline $\begin{array}{l}\text { Tela de arame Bezinal } \\
1,70 \mathrm{~mm}\end{array}$ & TAB & 32 & 1281 & 30 & 200 \\
\hline $\begin{array}{l}\text { Tela de arame inox } \\
\text { fino } 1,60 \mathrm{~mm}\end{array}$ & TAIF & 32 & 1226 & 30 & 200 \\
\hline $\begin{array}{l}\text { Tela de arame inox } \\
\text { grosso } 1,90 \mathrm{~mm}\end{array}$ & TAIG & 32 & 1707 & 30 & 200 \\
\hline
\end{tabular}

Foi realizada uma pesquisa com 21 empresas produtoras de tanque-rede no mercado nacional, no período de maio a junho de 2015. Esta pesquisa cobriu nove estados brasileiros: PR, SP, $\mathrm{MG}, \mathrm{BA}, \mathrm{MT}, \mathrm{PE}, \mathrm{GO}, \mathrm{CE}$, RO, que representam $72 \%$ da produção nacional de pescado (Produção..., 2013). O objetivo desta pesquisa foi obter o preço comercializado de telas para confecção de tanques-rede e a expectativa de durabilidade de cada material, segundo o entrevistado da empresa produtora.

Cada tipo de tela foi enrolado sobre o próprio eixo, pesado individualmente, e seu peso registrado em planilhas do software Excel® (Microsoft, 2016) (Fig. 1 A). Em seguida, as 
telas foram fixadas com abraçadeiras plásticas, com um espaçamento de $25 \mathrm{~cm}$ entre elas, a um sistema flutuador tubular confeccionado com três tubos de PVC de $100 \mathrm{~mm}$, fechado em suas extremidades. Os três tubos foram fixados paralelamente com uma distância de $1 \mathrm{~m}$ cada, com três peças de madeira para dar estabilidade ao sistema, que ficou totalmente submerso na água (Fig. 1 B). Os tanques-rede foram colocados na água no mesmo alinhamento, formando cinco blocos, com 40 telas (oito de cada modelo) amarradas a três tubos, e cada bloco ficou disposto a uma distância de $6 \mathrm{~m}$ (Fig. 1 C). A disposição das telas no tanque-rede permitiu a livre passagem da água através delas, além disso, o posicionamento do tanque-rede no lago contribuiu para que a corrente de água passasse por todas as telas ao mesmo tempo.
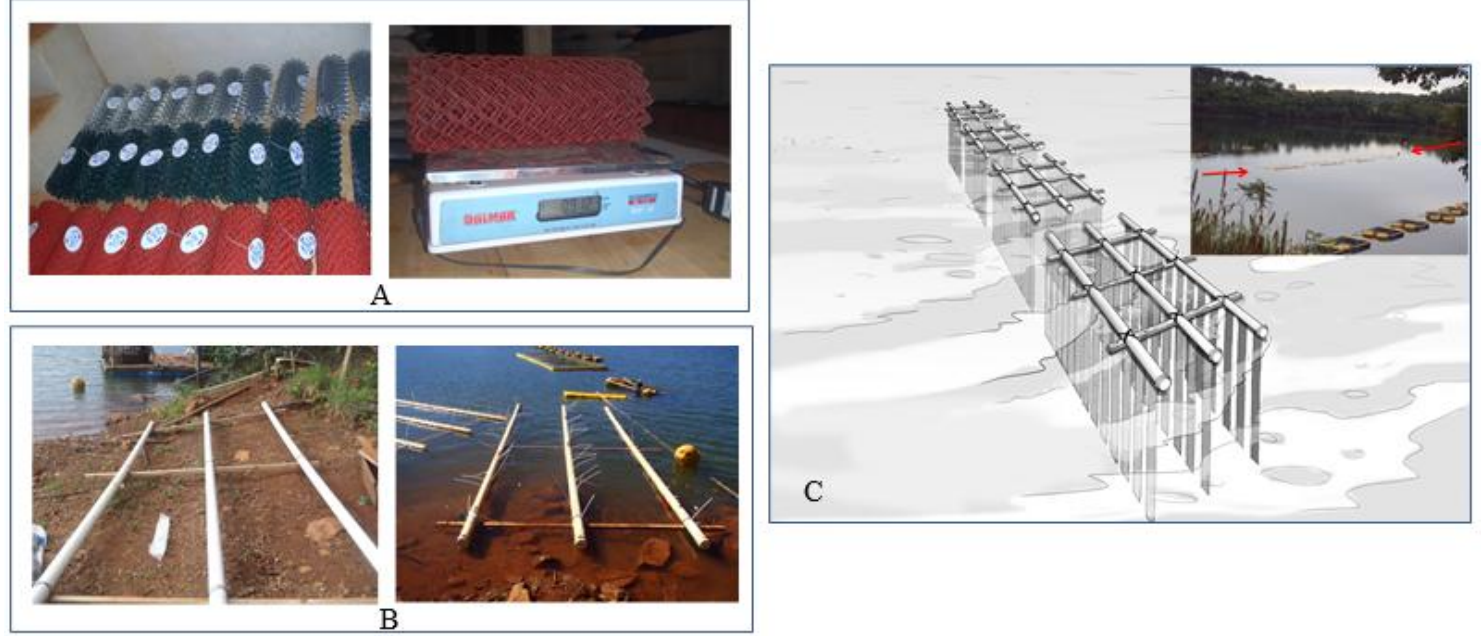

Figura 1. Modelo de montagem do tanque-rede. (A) Aferição do peso das telas, (B) confecção do sistema flutuador para a submersão das redes, (C) desenho esquemático e foto do posicionamento dos cinco blocos de teste entre as linhas de tanque-rede.

Foram realizadas cinco coletas de campo, sendo a primeira em junho de 2012 (t0), antes da instalação do tanque-rede contendo o peso inicial, e as demais com intervalos de seis meses entre elas, com término em 6 junho de 2014. As telas foram pesadas, e a quantidade de mexilhões aderidos a cada uma foi contada com o seguinte protocolo: coleta das telas no lago com barco, corte das abraçadeiras plásticas, ensacamento das telas no barco, retirada da água, retirada das telas no galpão de apoio, pesagem das telas em balança eletrônica, lavagem das telas com jato de água para a retirada do substrato recolhido em uma peneira com malha de $0,2 \mathrm{~mm}$, recolhimento e ensacamento do substrato para posterior contagem dos mexilhões-dourados, transporte do mexilhão-dourado no substrato, congelamento a $8^{\circ} \mathrm{C}$ do substrato para a preservação dele, contagem do mexilhão-dourado sobre uma mesa com luz natural a olho nu, registro do peso de cada tela e do número de mexilhões-dourados encontrados em planilhas eletrônicas do software Excel® (Microsoft, 2016).
O aumento de peso em razão da colmatação das telas foi calculado com base no peso inicial subtraído do peso encontrado ao final do período, de cada unidade amostral, e anotado em planilhas desenvolvidas para a coleta dos dados no software Excel ${ }^{\circledR}$ (Microsoft, 2016).

As análises estatísticas foram feitas com o pacote estatístico Stata ${ } / \mathrm{SE} \quad$ 12.0. Inicialmente, realizou-se uma análise descritiva e uma avaliação da variância entre grupos para definição do teste estatístico. A comparação do ganho de peso de cada tipo de tela foi realizada pelo teste estatístico de Kruskal-Wallis não paramétrico para mais de dois tratamentos. A escolha do teste foi em função de o ganho de peso das telas apresentar variâncias diferentes entre os grupos e da não normalidade dos dados, não solucionados após diferentes métodos de transformação de dados (Sampaio, 2007). 


\section{RESULTADOS E DISCUSSÃO}

Verificou-se, no "t1" com 180 dias (Tab. 2), que as telas dentro d'água não demonstraram a presença de mexilhões aderidos à tela. Esse fato pode estar associado com a fase de desenvolvimento inicial dos moluscos, isto é, aderência recente que não podia ser observada a olho nu ou ausência de aderência. Além disso, o período de instalação dos tanques-rede também pode ter contribuído, já que, no período de inverno, a temperatura média da água foi inferior a $18^{\circ} \mathrm{C}$, em comparação com as estações do ano mais quentes, nas quais a temperatura média fica acima de $22^{\circ} \mathrm{C}$ (Descrição..., 2012). Segundo Oliveira (2003), a reprodução do molusco cessa nas temperaturas entre 13 e $17^{\circ} \mathrm{C}$. Já em outro estudo, Santos (2004) observou densidades menores de $L$. fortunei sob temperaturas abaixo de $15^{\circ} \mathrm{C}$ ao avaliar a dinâmica e o crescimento desse molusco.

Na Tab. 2, observou-se no "t1" que as telas TAB e TAIF foram os grupos que menos colmataram e tiveram resultado igual; já as telas TAP, TAPP, TAIF foram os grupos que apresentaram resultado intermediário, e a tela TAIG apresentou a maior colmatação. Esses resultados são apresentados na Tab. 2, com as análises descritivas dos dados, como ganho de peso $(\mathrm{g})$ causado pela colmatação, desvio-padrão e o coeficiente de variação, além do número de observações.

Tabela 2. Resultados do ganho de peso das telas causados pela colmatação em relação ao intervalo de tempo das coletas

\begin{tabular}{|c|c|c|c|c|c|c|c|c|c|}
\hline Tipo de tela & Dados avaliados & "t1"180 & dias & $\begin{array}{r}\text { "t2"36 } \\
\text { dias } \\
\end{array}$ & & $\begin{array}{r}\text { "t3"5 } \\
\text { dia } \\
\end{array}$ & & "t4"720 & lias \\
\hline \multirow{4}{*}{ TAP } & Média (gramas) & 444 & \multirow{4}{*}{$\mathrm{b}$} & 599 & \multirow{4}{*}{$\mathrm{a}$} & 655 & \multirow{4}{*}{ b c } & 2710 & \\
\hline & Desvio-padrão (gramas) & 55 & & 260 & & 191 & & 806 & \\
\hline & Coeficiente de variação (\%) & $12 \%$ & & $43 \%$ & & $29 \%$ & & $30 \%$ & $\mathrm{a}$ \\
\hline & Número de observações & 8 & & 8 & & 7 & & 8 & \\
\hline \multirow{4}{*}{ TAPP } & Média (gramas) & 402 & \multirow{4}{*}{ b } & 416 & & 898 & \multirow{4}{*}{ b c } & 401 & \\
\hline & Desvio-padrão (gramas) & 91 & & 110 & & 362 & & 125 & \\
\hline & Coeficiente de variação (\%) & $23 \%$ & & $27 \%$ & $\mathrm{a}$ & $40 \%$ & & $31 \%$ & b \\
\hline & Número de observações & 8 & & 8 & & 8 & & 8 & \\
\hline \multirow{4}{*}{ TAB } & Média (gramas) & 268 & \multirow{4}{*}{$\mathrm{a}$} & 105 & & 386 & \multirow{4}{*}{$\mathrm{a}$} & 297 & \\
\hline & Desvio-padrão (gramas) & 92 & & 73 & h & 65 & & 106 & b \\
\hline & Coeficiente de variação (\%) & $34 \%$ & & $70 \%$ & $b$ & $17 \%$ & & $36 \%$ & b \\
\hline & Número de observações & 8 & & 8 & & 8 & & 7 & \\
\hline \multirow{4}{*}{ TAIF } & Média (gramas) & 334 & \multirow{4}{*}{$\mathrm{a} \mathrm{b}$} & 504 & & 596 & \multirow{4}{*}{$\mathrm{b}$} & 3091 & \\
\hline & Desvio-padrão (gramas) & 154 & & 304 & & 141 & & 1453 & \\
\hline & Coeficiente de variação (\%) & $46 \%$ & & $60 \%$ & $\mathrm{a}$ & $24 \%$ & & $47 \%$ & $a b$ \\
\hline & Número de observações & 8 & & 8 & & 8 & & 8 & \\
\hline \multirow{4}{*}{ TAIG } & Média (gramas) & 596 & \multirow{4}{*}{$\mathrm{c}$} & 506 & & 841 & \multirow{4}{*}{$\mathrm{c}$} & 2881 & \multirow{4}{*}{ a c } \\
\hline & Desvio-padrão (gramas) & 156 & & 295 & & 274 & & 603 & \\
\hline & Coeficiente de variação (\%) & $26 \%$ & & $58 \%$ & $\mathrm{a}$ & $33 \%$ & & $21 \%$ & \\
\hline & Número de observações & 8 & & 8 & & 8 & & 7 & \\
\hline
\end{tabular}

Letras iguais em cada coluna apresentam igualdade estatística para o teste de Kruskal-Wallis para valores de $\mathrm{P} \leq 0,05$. TAP - Tela de arame galvanizado plastificado. TAPP - Tela de arame galvanizado plastificado com tinta antiincrustante. TAB - Tela de arame Bezinal. TAIF - Tela de arame inox fino. TAIG- Tela de arame inox grosso.

As telas de arame plastificado, de uma forma geral, tiveram resultados equivalentes em termos estatísticos ao das telas de inox para ganho de peso em razão da colmatação, e as telas de arame Bezinal apresentaram os melhores resultados com os menores ganhos de peso. $\mathrm{Na}$ Tab. 2, são apresentados os resultados do material revestido plastificado com pintura anti- incrustante, com nível de colmatação intermediário quando comparado com os demais grupos.

Observou-se, na Tab. 3, no "t3" com 540 dias das telas dentro d'água, que a tela TAB teve o menor número de mexilhões aderidos em relação às outras telas. As telas TAP, TAPP, TAIF, 
TAIG apresentaram resultados intermediários para número de mexilhões-dourados aderidos, e não tiveram diferenças significativas $(\mathrm{P} \leq 0,05)$. As telas TAIF e TAIG apresentaram o maior resultado para número de mexilhões-dourados encontrados aderidos, e não tiveram diferenças significativas $(\mathrm{P} \leq 0,05)$. Quando os resultados são observados ao longo do tempo, pode-se notar forte colmatação total no período " $t 4$ " para as telas TAP, TAIF e TAIG, diferente do resultado observado para TAPP e TAB. Os resultados da análise estatística do número de mexilhõesdourados aderidos à tela estão na Tab. 3 .

Tabela 3. Resultado do número médio de mexilhões-dourados aderidos às telas nos tempos "t3 e t4"

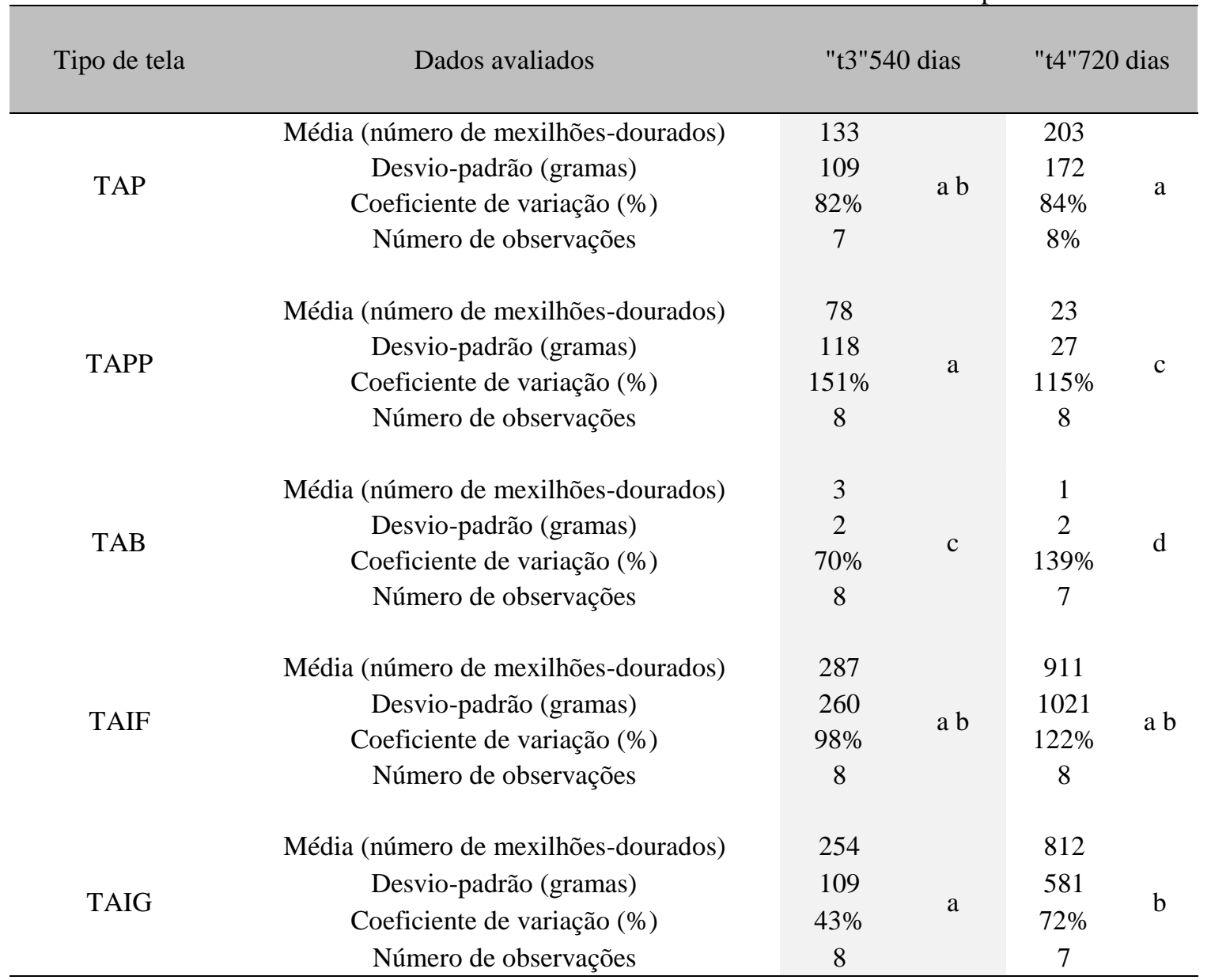

Letras iguais em cada coluna apresentam igualdade estatística para o teste de Kruskal-Wallis para valores de $\mathrm{P} \leq 0,05$. TAP - Tela de arame galvanizado plastificado.TAPP - Tela de arame galvanizado plastificado com tinta antiincrustante. TAB - Tela de arame Bezinal. TAIF - Tela de arame inox fino. TAIG- Tela de arame inox grosso.

A mesma análise foi efetuada para o tempo t4, a fim de qualificar a eficiência de cada grupo de telas, em relação à média da contagem de mexilhões-dourados aderidos encontrados.

A tela de arame Bezinal foi a que apresentou o menor número de mexilhões-dourados aderidos, seguida da tela de arame plastificado pintado com tinta anti-incrustante. Cabe destacar que, além de antiaderentes, esses dois materiais apresentaram características autolimpantes, pois o mexilhão-dourado aderido se soltou da tela do tempo "t3" para o tempo "t4" (Tab. 3). As telas de arame plastificado e de inox fino e grosso foram as que apresentaram o maior número de mexilhões-dourados aderidos, com resultado estatístico equivalente.

Com relação à pesquisa realizada com as 21 empresas, verificou-se que não foram 
encontrados os produtos TAPP e TAIG disponíveis para a compra, por ainda não ser uma prática do mercado brasileiro; além disso, o inox de diâmetro de $1,90 \mathrm{~mm}$ tem um custo elevado. No mercado brasileiro, o modelo de tanque-rede mais comum tem $2 \mathrm{~m}$ de largura $\mathrm{x} 2 \mathrm{~m}$ de comprimento $\mathrm{x} 2 \mathrm{~m}$ de profundidade, ou $8 \mathrm{~m}^{3}$ totais e $7,2 \mathrm{~m}^{3}$ de área útil.

Em cada ciclo de produção considerando as dimensões apresentadas, um tanque-rede tem uma receita bruta de $\mathrm{R} \$ 2.300,00$ e o investimento inicial da tela do tanque é da ordem de $\mathrm{R} \$$ 86,00/ano para a tela TAP. A cotação de preços de telas por metro quadrado, o nível de colmatação e a expectativa de durabilidade de um tanque-rede são apresentados na Tab. 4.

A expectativa de durabilidade de cada modelo de tanque-rede em relação ao material da tela foi informada pelos entrevistados, sendo de cinco anos para a TAP, 4,5 anos para a TAB e oito anos para a TAIF. A durabilidade da tela está relacionada com a qualidade da água, com a caraterística do material, bem como com o manejo do criatório, que inclui a lavagem das telas para a retirada da colmatação, geralmente entre ciclos de produção de peixes.

$\mathrm{O}$ fato de a tela $\mathrm{TAB}$ ter uma colmatação menor no mesmo período avaliado que as demais demonstra a importância no critério de escolha dos materiais para compor o tanque-rede, principalmente se a barragem do criatório estiver contaminada por mexilhão-dourado. Além de propiciar um ambiente mais adequado para os peixes de produção e melhor renovação de água e retirada dos catabólitos, o criatório terá um menor custo de limpeza da tela. Cabe ressaltar que vários materiais podem ser utilizados para a confecção de tanques-rede, como madeira, bambu, nylon, multifilamento, arame de aço carbono revestido com diversos tipos de polímeros e em aço inox, como descrito por Chagas et al. (2002) e Beveridge (2004).

Tabela 4 Descrição do nível de colmatação, durabilidade e cotação de preços das telas dos tanques-rede avaliadas no estudo por metro quadrado

\begin{tabular}{|c|c|c|c|}
\hline Item avaliado & $\begin{array}{c}\text { TAP } \\
\text { arame } 1,90 \mathrm{~mm} \\
\text { malha } 20 \mathrm{~mm} \\
\end{array}$ & $\begin{array}{c}\text { TAB } \\
\text { arame } 1,70 \mathrm{~mm} \\
\text { malha } 20 \mathrm{~mm} \\
\end{array}$ & $\begin{array}{l}\text { TAIF arame } 1,60 \mathrm{~mm} \\
\text { malha } 20 \mathrm{~mm}\end{array}$ \\
\hline Colmatação * & Médio & Baixo & Alto \\
\hline Expectativa de durabilidade (anos) & 5 & 4,5 & 8 \\
\hline Mediana dos preços tela $\mathrm{R} \$ / \mathrm{m}^{2}$ & $\mathrm{R} \$ 21,50$ & $\mathrm{R} \$ 22,00$ & $\mathrm{R} \$ 69,00$ \\
\hline Mediana dos preços tela US $\$ / \mathrm{m}^{2} * *$ & US\$ 5,60 & US\$ 5,79 & US\$ 18,16 \\
\hline Custo tela R $\$$ / ano $1 \mathrm{TR} * * *$ & $\mathrm{R} \$ 86,00$ & $\mathrm{R} \$ 97,80$ & $\mathrm{R} \$ 172,50$ \\
\hline Custo tela US\$ / ano 1TR $* *$ & US\$22,63 & US\$25,74 & US 45,39 \\
\hline
\end{tabular}

Observação*: Foi considerada com baixa colmatação a TAB, média a TAP, e alta a TAIF, quando se observa o período "t4" para colmatação total.

Observação**: A taxa cambial do dia da coleta era de US\$1,00 para R \$3,80.

Observação ***: O custo da tela/ano foi calculado com base na mediana do preço em reais encontrado, multiplicado por $20 \mathrm{~m}^{2}$ de tela utilizados para um tanque-rede de $2 \times 2 \times 2 \mathrm{~m}$, dividido pela expectativa de durabilidade em anos (ex.: TAP R $\$ 21,50$ x 20/5).

Verificou-se que a tela do tipo TAB poderia ser a melhor opção para manutenção da qualidade da água dentro do tanque-rede, pois foi a tela com menor peso, colmatação e número de mexilhões aderidos, além de apresentar um custo relativamente baixo em comparação com as outras. Esses resultados corroboram as recomendações da Embrapa (Piscicultura..., 2009), que descrevem que os materiais utilizados para a confecção dos tanques-rede devem ser funcionais, duráveis, resistentes à corrosão/apodrecimento e, ao mesmo tempo, de baixo custo.

É importante ressaltar que a alimentação fornecida aos peixes de produção nos tanquesrede das grandes barragens poderia aumentar o número de mexilhões-dourados, uma vez que há enriquecimento de nutrientes na água, favorecendo o desenvolvimento desses moluscos. Essa hipótese corrobora os estudos de Cataldo et al. (2012) e Boltovskoy et al. 
(2015), que demonstram que a presença de $L$. fortunei diminui as concentrações de matéria orgânica e aumenta as concentrações de amônia, nitratos e fosfatos.

É necessário, ainda, salientar que, ações estratégicas e táticas de limpeza nos arames galvanizados plastificados, de inox fino e grosso, podem apresentar ótimos resultados em termos econômicos e produtivos. Essa limpeza aumentaria a expectativa de durabilidade das telas e diminuiria os problemas causados pela colmatação do mexilhão-dourado. Além disso, um tanque-rede com uma tela autolimpante ou não aderente para o mexilhão-dourado poderia mitigar a colmatação pelo mexilhão-dourado nas barragens.

A tendência do sistema brasileiro de produção de peixe é o crescimento do tamanho e do volume do tanque-rede. A escolha de materiais menos colmatantes é muito importante, tendo em vista a dificuldade de manejar o tanque-rede de grande volume, além de causar estresse nos peixes, aumento dos custos de produção, risco de rompimentos das telas e risco de acidentes com os piscicultores. Outra forte tendência é o uso de equipamentos de limpeza da colmatação que permitam a permanência dos tanques-rede dentro da água por um maior período. Relevante se faz destacar que a colmatação retirada das telas tenha um destino adequado, para que haja a preservação do ambiente aquático.

\section{CONCLUSÃO}

Este estudo demonstrou que os diferentes materiais avaliados no revestimento dos arames das telas nos tanques-rede influenciam na colmatação e aderência do mexilhão-dourado. Observou-se que a tela de arame Bezinal (TAB) apresentou menor nível de colmatação, o que poderia levar a uma melhoria da produtividade, uma vez que prejuízos, como diminuição da qualidade da água, rompimento da tela devido ao peso e fuga dos peixes, além do risco de injúria aos tratadores, como cortes, e também aos peixes, poderiam ser evitados com o uso dessa tela. Observaram-se três condições diferentes em relação às telas, ou seja, a de menor custo, a mais durável e a com menor nível de colmatação. A tela mais eficiente quanto ao investimento ao ano no sistema produtivo de tanque-rede foi a de arame galvanizado plastificado, a tela com menor colmatação foi a de arame Bezinal, e a tela com melhor durabilidade foi a de inox fino, no entanto o seu custo/ano foi o dobro das demais. Verificou-se aderência do molusco L. fortunei nas telas após 540 dias de instalação dos tanques-rede, não sendo observada essa colmatação em intervalos de tempo inferiores. Tal situação pode ser justificada em virtude da fase de desenvolvimento inicial dos moluscos, ou seja, aderência recente, que não podia ser observada a olho nu, ou até mesmo a não aderência.

\section{REFERÊNCIAS}

AQUATIC Animal Health Code. Paris: OIE, 2013 Available in: <http://www.oie.int/internationalstandard-setting/aquatic-code/access-online>. Accessed in: 25 May 2014.

ARANA, L.V. Aquicultura e desenvolvimento sustentável: subsídios para a formulação de políticas de desenvolvimento da aquicultura brasileira. Florianópolis: UFSC, 1999. 310p.

ASSOCIAÇÃO BRASILEIRA DE NORMAS TÉCNICAS - ABNT. NBR - 10118. Tela de arame zincado de simples torção: especificação. 2.ed. Rio de Janeiro, 2013.

BEVERIDGE, M. Cage aquaculture. 3.ed. Oxford: Blackwell Publishing, 2004. 380p.

BOLETIM estatístico da pesca e aquicultura - Brasil 2008-2009. Brasília: Ministério da Pesca e Aquicultura, 2010.60p.

BOLTOVSKOY, D.; CORREA, N.; SYLVESTER, F.; CATALDO, D. Nutrient recycling, phytoplankton grazing, and associated impacts of Limnoperna fortunei. limnoperna fortune. invading nature - springer series in invasion ecology. New York: Springer, 2015. v.10, p.152-176.

BORGHETTI, N.R.B.; OSTRENSKY, A.; BORGHETTI, J.R. Aquicultura - uma visão geral sobre a produção de organismos aquáticos no Brasil e no mundo. Curitiba: Grupo Integrado de Aquicultura e Estudos Ambientais, 2003. 128p.

BRABO, M.F.; VERAS, G.C.; PAIVA, R.S.; FUJIMOTO, R.Y. Aproveitamento aquícola dos grandes reservatórios brasileiros. Bol. Inst. Pesca, v.40, p.121-134, 2014.

CASTRO, I.B.; WESTPHAL, E.; FILLMANN, G. Tintas anti-incrustantes de terceira geração: novos biocidas no ambiente aquático. Quim. Nova, v.34, p.1021-1031, 2011. 
CATALDO, D.I.; O’FARRELL, V.; PAOLUCCI, F. et al. Impact of the invasive golden mussel (Limnoperna fortunei) on phytoplankton and nutrient cycling. Aquat. Invasions, v.7, p.91-100, 2012.

CHAGAS, E.C.; LOURENÇO, J.N.P.; GOMES, L.C.; ROUBACH, R. Seleção de materiais para a construção de tanques-rede. Manaus: Embrapa/CPAA, 2002. 4p. (Comunicado técnico, 14).

CHOMEL, B.B. Bioterrorism and invasive species. Rev. Sci. Tech. Off. Int. Epizoot., v.29, p.193-199, 2010.

DARRIGRAN, G.; EZCURRA DE DRAGO, I. Distribución de (Dunker, 1857) (Mytilidae) em la cuenca del Plata, Región Neotropical. Limnoperna Fortunei Meio Ambien., v.13, p.75-79, 2000.

DESCRIÇÃO e diagnóstico da unidade hidrográfica dos afluentes do baixo Iguaçu com vistas à criação do comitê de bacia. 2012. 15p. Disponível em: <http://www.recursoshidricos.pr.gov.br/arquivos/File/ CERH_-_19_RO/caracterizacao_

diagnostico_ugrhi_baixo_iguacu.pdf $>$. Acesso em: 21 set. 2015 .

HELLIO, C.; YEBRA, D. (Eds.). Advances in marine antifouling coatings and technologies. Cambridge: Woodhead, 2009. 784p.

KUBITZA, F. Qualidade da água no cultivo de peixes e camarões. Jundiaí, SP: F. Kubitza, 2003. 229p.

MICROSOFT corporation office / Excel 2016. Planilha eletrônica Excel. Portland: Microsoft Research, 2016.

OIE listed diseases, infections and infestations in force in 2014. Available in: <http://www.oie.int/animalhealth-in-the-world/oie-listed-diseases-2014/> . Accessed in: 10 Aug. 2017.

OLIVEIRA, M.D. Ocorrência e impactos do Mexilhão Dourado (Limnoperna fortunei, Dunker 1857) no Pantanal Mato-Grossense. Brasília: Embrapa, 2003. 6p. (Circular Técnica, n.38).
OLIVEIRA, M.D.; PELLEGRIN, L.A.; BARRETO, R.R. et al. Área de ocorrência do Mexilhão Dourado (Limnoperna fortunei) na Bacia do Alto Paraguai, entre os anos de 1998 e 2004. Corumbá, MS: Embrapa/CPAP, 2004. 19p. (Documentos, n.64).

ONO, E.A.; KUBITZA, F. Cultivo de peixes em tanques-rede. 3.ed. Jundiai, SP: Ono, 2003. 112p.

OSTRENSKY, A.; BORGUETTI, J.R.; SOTO, D. Aquicultura no Brasil: o desafio é crescer. Brasília: Secretaria Especial de Aquicultura e Pesca/ Food and Agriculture Organization, 2008. 276p.

PISCICULTURA em tanques-rede / Embrapa Amazônia Oriental. Brasília, DF: Embrapa Informação Tecnológica, 2009. 120p. (Coleção Criar, n.6)

PLANO safra da pesca e aquicultura 2012/2013. [Brasília]: Ministério da Pesca e Aquicultura, 2014. $15 \mathrm{p}$.

PRODUÇÃO da pecuária municipal 2013. Rio de Janeiro: IBGE, 2013. v.41, 108p. Disponível em: http://www.ibge.gov.br/home/estatistica/economia/pp $\mathrm{m} / 2013$ / default

xls_grandes_regioes.shtm>. Acessado em 05 mai. 2015.

PRODUÇÃO da pecuária municipal 2015. Rio de Janeiro: IBGE, 2015. v.43, p.1-49.

SAMPAIO, I.B.M. Estatística aplicada à experimentação animal. 3.ed. Belo Horizonte: FEPMVZ, 2007. 264p

SANTOS, C.P. Avaliação da densidade e crescimento populacional do mexilhão dourado Limnoperna fortunei (Dunker, 1857) em suas diferentes fases de vida no Lago Guaíba, município de Porto Alegre, RS, como subsídios ao controle do bivalve invasor. 2004. 106f. Dissertação (Mestrado em Ecologia) Universidade Federal do Rio Grande do Sul, Porto Alegre, RS. Disponível em: <http://www.lume.ufrgs.br/handle/10183/5430>Acesa do em: 10 set. 2017.

SCORVO FILHO, J.D.; FRASCÁ-SCORVO, C.M.D.; ALVES, J.M.C.; SOUZA, F.R.A. A tilapicultura e seus insumos, relações econômicas. Rev. Bras. Zootec., v.39, Supl. Esp., p.112-118, 2010.

SILVA, J.S.V.; SOUZA, R.C.C.L. (Orgs.). Água de lastro e bioinvasão. Rio de Janeiro: Interciência, 2004. 224p.

SOUZA, R.C.C.L.; CALAZANS, S.H.; SILVA, E.P. Impacto das espécies invasoras no ambiente aquático. Cienc. Cult. v.61, p.35-41, 2009.

THE STATE of world fisheries and aquaculture. Rome: FAO; 2009. 